\title{
ANALISIS BUDAYA KESELAMATAN KERJA PEGAWAI \\ DI BIRO PERENCANAAN (BP) - BADAN TENAGA NUKLIR NASIONAL (BATAN)
}

\author{
Sri Agustini, Budi Kaliwanto \\ Biro Perencanaan (BP) - Badan Tenaga Nuklir Nasional (BATAN), Indonesia \\ agustin@batan.go.id, budi-k@batan.go.id
}

\begin{abstract}
Abstrak: Analisis Budaya Keselamatan Keselamatan Kerja Pegawai di Biro Perencanaan - BADAN TENAGA NUKLIR NASIONAL (BATAN). Penelitian ini bertujuan untuk mengetahui budaya keselamatan kerja pegawai di BP BATAN dan mengidentifikasi profil budaya organisasi pada jajaran pimpinan. Hasil penilaian budaya keselamatan kerja pegawai di BP BATAN masuk dalam kategori Baik. Penelitian deskriptif dengan interprestasi dan analisis kuantitatif ini memperoleh hasil penilaian diri dari 5 Karakteristik dan 37 Atribut Budaya Keselamatan di BP BATAN yang terdiri dari penilaian pejabat struktural sebanyak 13 orang dengan hasil penilaian diri budaya keselamatan 3,93 dengan kategori Baik. Pejabat fungsional sebanyak 11 orang dengan hasil penilaian diri budaya keselamatan 3,73 dengan kategori $\mathrm{B}$, dan non struktural-non fungsional sebanyak 13 orang dengan hasil penilaian diri budaya keselamatan 3,64 dengan kategori B. Sedangkan hasil penilaian diri BP dari 33 pegawai BP dengan hasil penilaian diri budaya keselamatan 3,78 dengan kategori B. Hasil analisis juga menunjukkan bahwa budaya keselamatan kerja pegawai yang melibatkan antar bidang dan keahlian kurang berjalan dengan baik di BP, sikap saling percaya belum sepenuhnya meresap pada semua pegawai.
\end{abstract}

Kata kunci: Budaya Keselamatan Kerja Pegawai, Budaya organsasi, Pegawai BP

\begin{abstract}
Analysis of Employee Safety Culture in the Planning Bureau - NUCLEAR NUCLEAR AGENCY (BATAN). This study aims to understand the work safety culture at $B P$ BATAN and improve the organizational culture profile at the leadership level. Results The work safety culture award at BP BATAN is in the Good category. Descriptive research with interpretation and quantitative analysis obtained the results of self-assessment of 5 Characteristics and 37 Attributes of Safety Culture in BP BATAN consisting of 13 structural permits with Good Cultural Safety 3.93 results with Good category. Functional Officials A total of 11 people with cultural safety results of 3.73 with category $B$, and nonfunctional non-functional as many as 13 people with results Improve safety culture 3.64 with category $B$. Results produced by BP themselves from 33 BP employees with assessment results self safety culture 3.78 with category $B$. The results of the analysis also show that work safety culture that involves interdisciplinary and expertise is not going well at BP, incompatible mutual trust pervades all employees.
\end{abstract}

Keywords: Employee Safety Culture, Organizational Culture, BP Employees

\section{PENDAHULUAN}

Undang undang Nomor 10 Tahun 1997 Tentang Ketenaganukliran sebagai dasar hukum pemanfaatan tenaga nuklir di Indonesia menekankan pentingnya budaya keselamatan. Dalam Peraturan Pemerintah (PP) Nomor 33 Tahun 2007 Tentang Budaya Keselamatan juga mengisyaratkan pentingnya budaya keselamatan. Untuk mewujudkan keselamatan dalam setiap pelaksanaan kegiatan di BATAN, disusun Peraturan Kepala (Perka) BATAN Nomor 
200/KA/X/2012 tentang Pedoman Pelaksanaan Penerapan Budaya Keselamatan. Pedoman tersebut disusun untuk menumbuh-kembangkan budaya keselamatan. Budaya keselamatan melibatkan siapapun yang sikap dan perilakunya dapat berpengaruh terhadap keselamatan nuklir, bukan hanya operator penguasa instalasi nuklir melainkan juga kepada pegawai yang non operator instalasi nuklir atau pelayanan. pegawai BATAN wajib mengutamakan keselamatan dalam setiap pelaksanaan kegiatannya, dengan tanggung jawab yang dilaksanakan secara berjenjang, dari setiap potensi bahaya yang dapat timbul akibat proses bisnis yang dilakukan agar dapat melindungi setiap pegawai, fasilitas, masyarakat dan lingkungan tempat kerja. Pencapaian tingkat keselamatan dalam bekerja diperlukan suatu aturan keselamatan yang diacu oleh seluruh unit kerja maupun individu di BATAN, sehingga setiap proses bisnis yang dilakukan dapat diidentifikasi terhadap potensi bahaya yang dapat ditimbulkan sehingga risiko kecelakaan yang mungkin timbul dapat dikendalikan. Untuk itu perlu dibuat suatu persyaratan dalam bekerja, standar acuan kerja, perencanaan, hingga penggkajian secara manajemen, teknologi serta sifat dan sikap individu sebagai pelaksana proses bisnis. Setiap organisasi memiliki budaya yang dapat memberi pengaruh bermakna terhadap sikap dan perilaku dari anggotanya. Kompetensi dan nilai-nilai dari staf dan pimpinan memegang peranan kunci yang menentukan efektifitas dan keberhasilan organisasi (Iriviranty, 2014).

Biro Perencanaan (BP) bukan organisasi riset, tidak memiliki fasilitas reaktor nuklir, laboratorium pendukung, dan bukan pengguna zat radioaktif. Akan tetapi dalam melaksanakan tugasnya, BP juga perlu menerapkan budaya keselamatan untuk mencapai sasaran dan tujuan meningkatkan mutu layanan. Evaluasi atau penilaian secara berkala perlu dilakukan untuk mengetahui sejauh mana penerapan budaya keselamatan organisasi dan personil BP. Metode penilaian dilakukan secara self-assessment melalui survei dengan menyebarkan kuesioner berdasarkan Perka BATAN Nomor 200 Tahun 2012 yang dirancang untuk mengukur baik karaketeristik maupun atribut budaya keselamatan terhadap semua tingkatan manajemen di BP. Hasil analisis data kedua parameter tersebut menunjukkan nilai yang beragam. Hasil penilaian budaya keselamatan organisasi BP pada tahun 2018 mendapatkan peringkat baik. Terdapat karakteristik dan atribut yang menunjukkan beberapa kelemahan yang berkontribusi negatif terhadap skor total.

Dalam memahami budaya keselamatan, diperlukan pendekatan wawasan tentang konsep budaya. Langkah pertama adalah untuk mendapatkan pengertian budaya dalam arti luas. Definisi budaya yang paling sederhana adalah "tata cara manusia melakukan sesuatu di sekitarnya". Ekologi adalah lingkungan pembentuk budaya yang tampak di permukaan, dan kemudian budaya pembentuk perilaku-perilaku khusus. Cara berpikir yang sederhana tentang budaya adalah menempatkannya di antara ekologi dan perilaku sosial. Salah satu cara mengerti tentang budaya keselamatan organisasi adalah dengan mengetahui Karakteristik budaya keselamatan sebagai 
strategi untuk mengukur, mengidentifikasi dan menumbuh-kembangkan budaya keselamatan yang mencakup sikap dan perilaku yang terstruktur. Karakteristik budaya keselamatan juga dapat ditafsirkan sebagai serangkaian proses berinteraksi dari setiap individu yang terlibat memberikan kontribusi untuk mencapai kinerja keselamatan yang tinggi. Berdasarkan Perka BATAN Nomor 200 Tahun 2012, budaya keselamatan terdiri dari 5 (lima) karakteristik seperti pada Tabel 1, dan diuraikan menjadi 37 atribut budaya keselamatan, sebagaimana yang diuraikan dalam Lampiran Bab II dan Anak Lampiran A Perka tersebut. Survei didesain untuk mengukur opini pegawai BP mengenai isu keselamatan kerja pegawai BP. Survei terdiri dari 5 Karakteristik dan 37 Atribut Budaya Keselamatan.

\section{METODE}

Penelitian ini adalah penelitian deskriptif menggunakan interpretasi analisis data kualitatif dengan desain cross sectional. Berdasarkan tujuan penelitian, maka penelitian ini merupakan penelitian eksplorasi untuk mengukur budaya keselamatan kerja pegawai indentifikasi profil budaya organisasi. Hasil dari pengukuran ini digunakan sebagai panduan dalam mengembangkan budaya keselamatan kerja pegawai (Iriviranty, 2014). Data yang digunakan dalam penelitian ini adalah data kuantitatif yang diperoleh dari data yang diolah dari seluruh pegawai BP (Pratami, 2017) dengan jumlah 37 pegawai. Teknik pengambilan sampel dilakukan oleh 37 pegawai BP yang mengisi kuesioner dari 37 pegawai hanya 33 pegawai yang mengisi kuesioner sedangkan 4 pegawai tidak Badan Tenaga Nuklir Nasional (BATAN) pada tanggal 11 Oktober 2018.

Metode pengumpulan data dalam penelitian ini dilakukan dengan menggunakan metode survey melalui angket (kuesioner) guna mendapatkan data primer, dan untuk mendapatkan data berupa gambaran umum pegawai BP dilakukan melalui wawancara langsung kepada nara sumber. Kuesioner adalah daftar pertanyaan yang diisi oleh responden (Masinambow, n.d.).

Subjek penelitian 33 pegawai di Biro Perencanaan BATAN untuk dan Lokasi penelitian dilakukan di Biro Perencanaan, Kantor Pusat BATAN, Jakarta. Waktu yang diperlukan untuk menyelesaikan penelitian adalah 3 bulan. Penilaian ini dilaksanakan di Biro Perencanaan, Badan Tenaga Nuklir Nasional (BATAN) pada tanggal 11 Oktober 2018. Pengolahan data dilakukan secara bertahap, meliputi: editing, coding, dan tabulating dengan menggunakan aplikasi exel dan penghitungan dengan komputer. Teknik pengumpulan data dan informasi dalam penelitian ini menggunakan hasil kuesioner.

\section{HASIL DAN PEMBAHASAN}


Hasil kuesioner 33 responden di Biro Perencanaan, dapat dilihat pada tabel berikut:Hasil evaluasi 5 karakteristik dari 37 atribut budaya keselamatan dari 34 responden yang perlu ditindaklanjuti sebanyak 85 komentar, dapat dilihat pada tabel berikut:

\section{Hasil Penilaian Diri Budaya Keselamatan Pejabat Struktural BP}

Pada Tabel 1 dan Gambar 1, hasil penilaian diri pejabat struktural unsur tertinggi pada karakteriatik "Adanya kepemimpinan dalam keselamatan". Hal tersebut menunjukkan bahwa para pejabat struktural di BP memiliki perhatian, komitmen, tanggung jawab dan keterlibatan langsung dalam hal keselamatan. Nilai terendah terjadi pada karakteristik "Keselamatan terintegrasi dalam setiap kegiatan", yang menunjukkan bahwa sikap saling percaya belum sepenuhnya meresap pada semua pegawai, para pejabat struktural belum sepenuhnya menerapkan keselamatan nuklir dan keselamatan lingkungan, dan dianggap belum mengupayakan kondisi kerja yang baik dengan mempertimbangkan tekanan waktu, beban kerja dan stres yang dirasakan dalam pelaksanaan pekerjaan.

Tabel 1. Hasil Penilaian Diri Budaya Keselamatan Pejabat Struktural BP Tahun 2018

\begin{tabular}{|l|c|c|c|c|}
\multicolumn{1}{|c|}{ Karakteristik } & Nilai & $\begin{array}{c}\text { Konversi ke } \\
\text { skala 1000 }\end{array}$ & $\begin{array}{c}\text { Kategori } \\
\text { Rangking }\end{array}$ & Baik \\
\hline $\begin{array}{l}\text { Keselamatan sebagai nilai yang } \\
\text { diakui }\end{array}$ & 4,03 & 805,56 & B \\
\hline $\begin{array}{l}\text { Adanya kepemimpinan dalam } \\
\text { keselamatan }\end{array}$ & 4,06 & 811,67 & B \\
\hline $\begin{array}{l}\text { Adanya akuntabilitas dalam } \\
\text { keselamatan }\end{array}$ & 3,90 & 780,00 & Baik \\
\hline $\begin{array}{l}\text { Keselamatan terintegrasi dalam } \\
\text { setiap kegiatan }\end{array}$ & 3,78 & 755,56 & Baik \\
\hline $\begin{array}{l}\text { Keselamatan merupakan } \\
\text { penggerak pembelajaran }\end{array}$ & 3,88 & 776,19 & Baik \\
\hline Nilai survey Pejabat Struktural & 3,93 & 785,79 & B & Baik \\
\hline
\end{tabular}

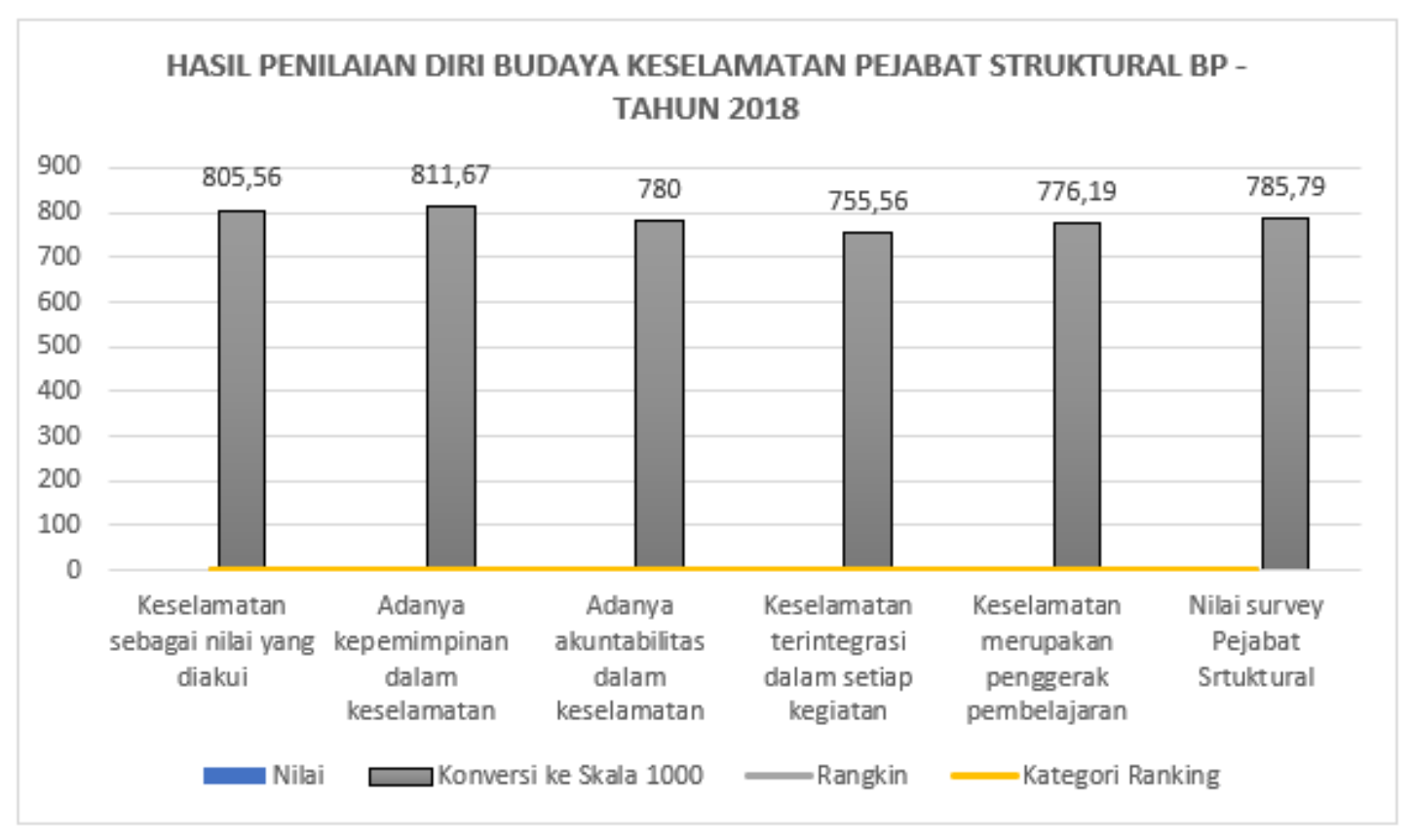

Gambar 1. Hasil Penilaian Diri Budaya Keselamatan Pejabat Struktural BP Tahun 2018 
Dari hasil penilaian yang dilakukan oleh koresponden pejabat struktural untuk 5 karakteristik dari 37 atribut, budaya keselamatan dilingkungan pejabat struktural BP dalam kategori Baik. Capaian ini masih dapat ditingkatkan terutama pada karakteristik "Keselamatan terintegrasi dalam setiap kegiatan".

\section{Hasil Penilaian Diri Budaya Keselamatan Pejabat Fungsional}

Pada Tabel 2 dan Gambar 2, hasil penilaian diri Budaya Keselamatan Pejabat Fungsional unsur tertinggi pada karateristik "Keselamatan merupakan penggerak pembelajaran". Hal tersebut terutama dapat dilihat bahwa BP mendorong setiap orang untuk melaporkan kondisi dan/atau perilaku yang berbahaya (tidak selamat) secara bebas dan terbuka sesuai dengan prosedur yang berlaku, mengembangkan kompetensi setiap pegawai secara baik dan sistematis. Sedangkan unsur terendah pada karateristik "Adanya kepemimpinan dalam keselamatan", terutama terlihat bahwa BP masih dianggap kurang menjamin ketersediaan pegawai dengan jumlah cukup dan berkompeten, keterampilan kepemimpinan di BP kurang dikembangkan secara sistematis, serta pejabat struktural di BP masih kurang dalam meningkatkan kemampuan untuk menyelesaikan konflik yang ada.

Tabel 2. Hasil Penilaian Diri Budaya Keselamatan Pejabat Fungsional BP Tahun 2018

\begin{tabular}{|l|c|c|c|c|}
\hline \multicolumn{1}{|c|}{ Karateristik } & Nilai & $\begin{array}{c}\text { Konversi ke Skala } \\
1000\end{array}$ & Rangking & $\begin{array}{c}\text { Kategori } \\
\text { Rangking }\end{array}$ \\
\hline $\begin{array}{l}\text { Keselamatan sebagai nilai } \\
\text { yang diakui }\end{array}$ & 3,73 & 746,15 & B & Baik \\
\hline $\begin{array}{l}\text { Adanya kepemimpinan } \\
\text { dalam keselamatan }\end{array}$ & 3,65 & 729,23 & B & Baik \\
\hline $\begin{array}{l}\text { Adanya akuntabilitas dalam } \\
\text { keselamatan }\end{array}$ & 3,75 & 750,77 & B & Baik \\
\hline $\begin{array}{l}\text { Keselamatan terintegrasi } \\
\text { dalam setiap kegiatan }\end{array}$ & 3,75 & 750,43 & B & Baik \\
\hline $\begin{array}{l}\text { Keselamatan merupakan } \\
\text { penggerak pembelajaran }\end{array}$ & 3,79 & 758,24 & B & Baik \\
\hline $\begin{array}{l}\text { Nilai survey Pejabat } \\
\text { Fungsional }\end{array}$ & 3,73 & 746,96 & B & \\
\hline
\end{tabular}




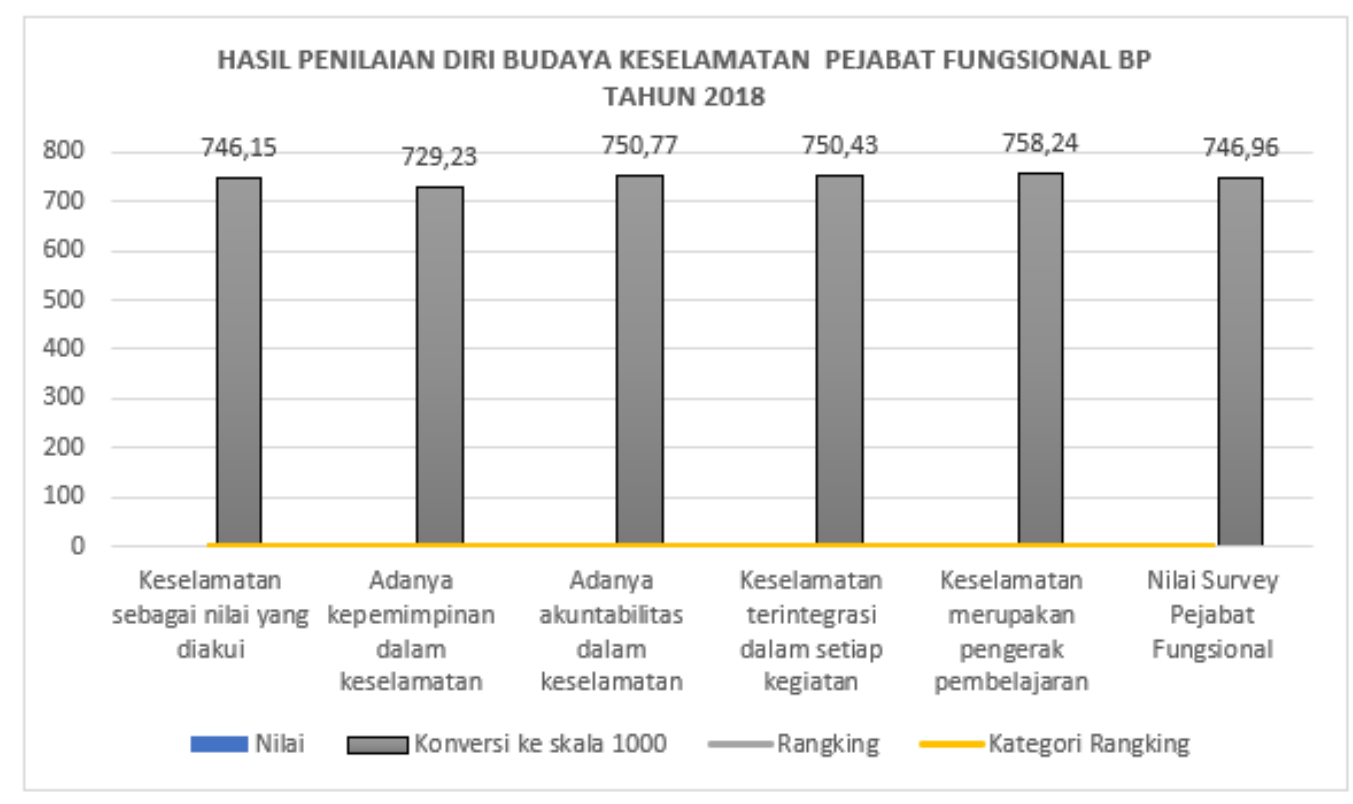

Gambar 2. Hasil Penilaian Diri Budaya Keselamatan Pejabat Fungsional BP Tahun 2018

Hasil penilaian yang dilakukan oleh koresponden pejabat fungsional dari 5 karakteristik dari 37 atribut budaya keselamatan dilingkungan pejabat fungsional BP masih dalam kategori Baik. Capaian ini masih dapat ditingkatkan terutama pada karakteristik "Adanya kepemimpinan dalam keselamatan".

\section{Hasil Penilaian Diri Budaya Keselamatan Pejabat Non Struktural dan Non Fungsional}

Pada Tabel 3 dan Gambar 3, hasil penilaian diri Budaya Keselamatan non pejabat struktural dan non fungsional, unsur tertinggi pada karakteristik "Keselamatan merupakan penggerak pembelajaran", terutama terlihat pada sikap mau bertanya sudah terbangun pada semua orang, BP mendorong setiap orang untuk melaporkan kondisi dan/atau perilaku yang berbahaya (tidak selamat) secara bebas dan terbuka sesuai dengan prosedur yang berlaku. Sedangkan unsur terendah pada karakteristik “Adanya kepemimpinan dalam keselamatan”. Hal ini disebabkan karena faktor kepemimpinan dalam keselamatan di BP dianggap kurang terlihat dari keterlibatan pejabat struktural pada kegiatan yang berhubungan dengan keselamatan, komitmen keselamatan dari pejabat struktural di BP kurang terlihat dalam pelaksanaan tugas dan tanggung jawabnya, BP kurang mempertimbangkan implikasi terhadap keselamatan dari proses perubahan yang terjadi, baik perubahan prosedur dan/atau peralatan dan/atau organisasi.

Tabel 3. Hasil Penilaian Diri Budaya Keselamatan Pejabat Non Struktural dan Non Fungsional 


\begin{tabular}{|l|c|c|c|c|}
\hline \multicolumn{1}{|c|}{ Karakteristik } & Nilai & $\begin{array}{c}\text { Konversi ke } \\
\text { Skala 1000 }\end{array}$ & Rangking & $\begin{array}{c}\text { Kategori } \\
\text { Rangking }\end{array}$ \\
\hline $\begin{array}{l}\text { Keselamatan sebagai nilai } \\
\text { yang diakui }\end{array}$ & 3,58 & 717 & B & Baik \\
\hline $\begin{array}{l}\text { Adanya kepemimpinan dalam } \\
\text { keselamatan }\end{array}$ & 3,54 & 708 & B & Baik \\
\hline $\begin{array}{l}\text { Adanya akuntabilitas dalam } \\
\text { keselamatan }\end{array}$ & 3,65 & 730 & B & Baik \\
\hline $\begin{array}{l}\text { Keselamatan terintegrasi } \\
\text { dalam setiap kegiatan }\end{array}$ & 3,64 & 728 & B & Baik \\
\hline $\begin{array}{l}\text { Keselamatan merupakan } \\
\text { penggerak pembelajaran }\end{array}$ & 3,77 & 754 & B & Baik \\
\hline $\begin{array}{l}\text { Nilai survey non struktural dan } \\
\text { non fungsional }\end{array}$ & 3,64 & 727 & & \\
\hline
\end{tabular}

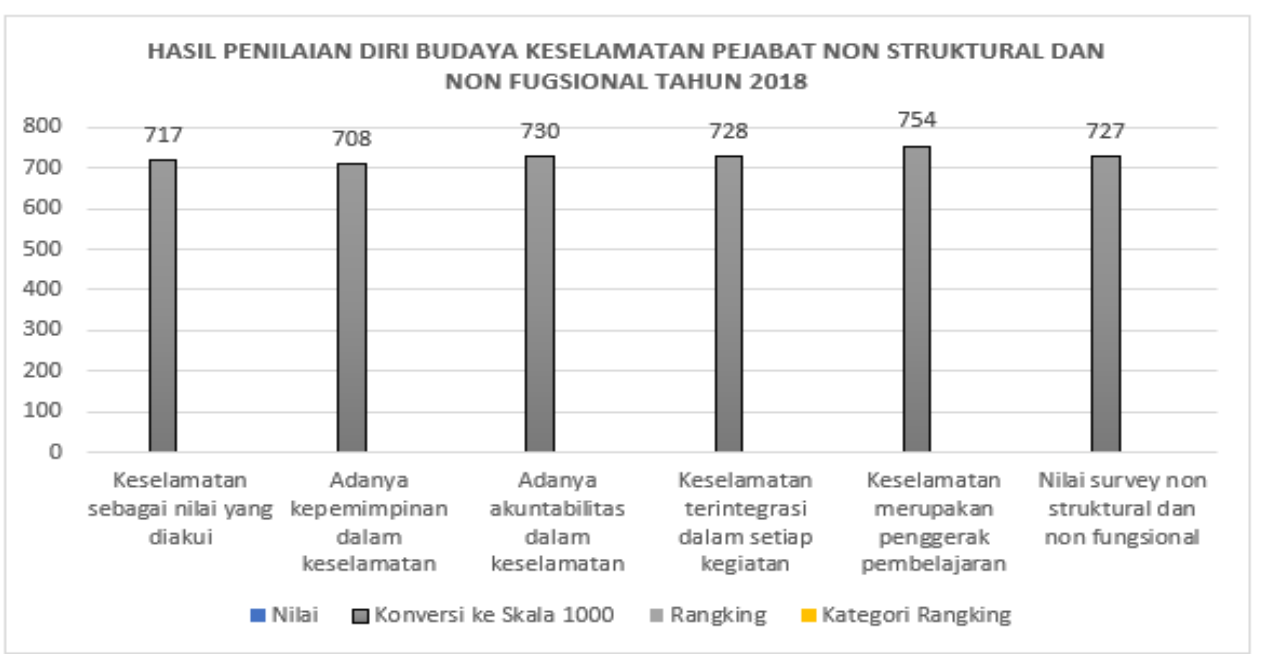

Gambar 3. Hasil Penilaian Diri Budaya Keselamatan Pejabat Non struktural dan Non Fungsional

Dari hasil penilaian yang dilakukan oleh koresponden pejabat non struktural dan non fungsional terhadap 5 karakteristik dari 37 atribut budaya keselamatan, terlihat bahwa nilai masih dalam kategori Baik. Capaian ini masih dapat ditingkatkan terutama pada karakteristik “Adanya kepemimpinan dalam keselamatan".

\section{Hasil Penilaian Diri Budaya Keselamatan Biro Perencanaan}

Pada Tabel 4 dan Gambar 4, hasil penilaian diri 34 pegawai BP unsur tertinggi pada karakteristik "Keselamatan merupakan penggerak pembelajaran", terutama terlihat pada anggapan bahwa BP mendorong setiap orang untuk melaporkan kondisi dan/atau perilaku yang berbahaya (tidak selamat) secara bebas dan terbuka sesuai dengan prosedur yang berlaku, BP dinilai telah mengembangkan kompetensi setiap pegawai secara baik dan sistematis, BP telah menggunakan hasil audit, penilaian internal dan eksternal serta hasil penilaian diri untuk mengevaluasi pelaksanaan pekerjaan, dan BP telah selalu memantau, mengevaluasi dan meningkatkan indikator kinerja keselamatan untuk mencapai hasil yang baik. Unsur terendah pada karakteristik "Keselamatan terintegrasi dalam setiap kegiatan". Hal ini dinilai bahwa kerja sama yang melibatkan antar bidang dan keahlian kurang berjalan dengan baik di BP, sikap saling percaya belum sepenuhnya meresap pada semua pegawai. 


\begin{tabular}{|l|c|c|c|c|}
\hline \multicolumn{1}{|c|}{ Karakteristik } & Nilai & $\begin{array}{c}\text { Konversi ke } \\
\text { Skala 1000 }\end{array}$ & Rangking & $\begin{array}{c}\text { Kategori } \\
\text { Rangking }\end{array}$ \\
\hline $\begin{array}{l}\text { Keselamatan sebagai nilai } \\
\text { yang diakui }\end{array}$ & 3,80 & 761 & B & Baik \\
\hline $\begin{array}{l}\text { Adanya kepemimpinan dalam } \\
\text { keselamatan }\end{array}$ & 3,77 & 754 & B & Baik \\
\hline $\begin{array}{l}\text { Adanya akuntabilitas dalam } \\
\text { keselamatan }\end{array}$ & 3,78 & 756 & B & Baik \\
\hline $\begin{array}{l}\text { Keselamatan terintegrasi } \\
\text { dalam setiap kegiatan }\end{array}$ & 3,73 & 747 & B & Baik \\
\hline $\begin{array}{l}\text { Keselamatan merupakan } \\
\text { penggerak pembelajaran }\end{array}$ & 3,82 & 764 & B & Baik \\
\hline Nilai survey BP & 3,78 & 756 & B & \\
\hline
\end{tabular}

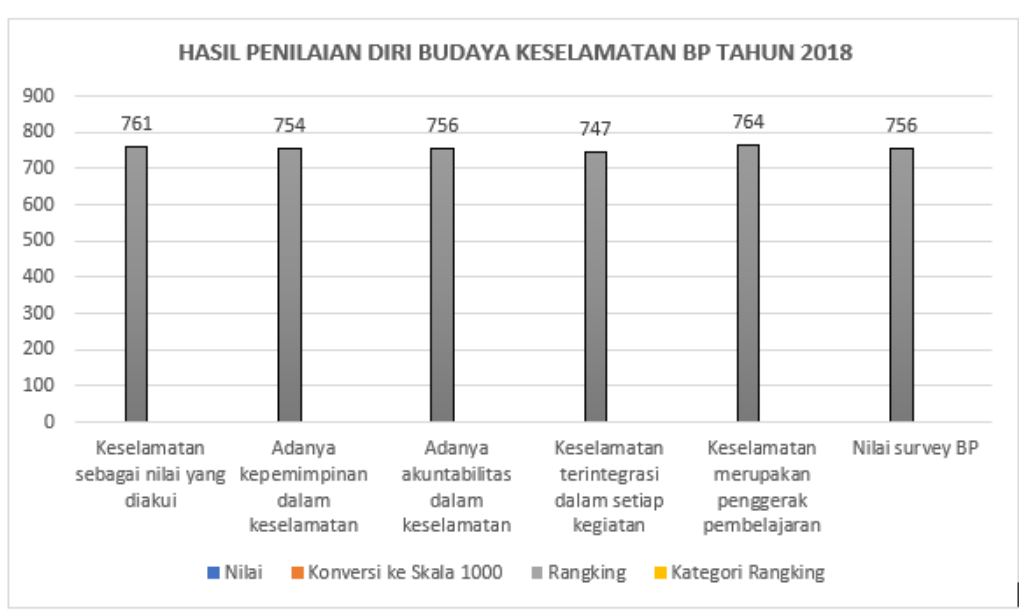

Gambar 1. Hasil Penilaian Diri Budaya Keselamatan BP Tahun 2018

Hasil nilai survei penilaian diri dari 5 karakteristik budaya keselamatan di BP tahun 2018 mendapat nilai 3,78 $(756,27)$ dengan kategori Baik. Hal tersebut menunjukkan bahwa pegawai BP sangat peduli dengan adanya budaya keselamatan kerja pada setiap kegiatan yang dilakukan.

\section{KESIMPULAN}

Berdasarkan pembahasan dan kesimpulan penelitian di atas dapat dijabarkan sebagai berikut: a) Hasil penilaian diri budaya keselamatan BP tahun 2018 menghasilkan skor 756,27 yang termasuk kedalam peringkat B (baik). b) Terdapat karakteristik dengan prosentase pemenuhan dibawah ratarata yaitu karakteristik 2, 3 dan 4. c) Hasil survei Budaya Keselamatan di BP bermanfaat untuk menyusun program kerja spesifik sesuai dengan karakteristik Budaya Keselamatan. d) Melalui survei Budaya Keselamatan pegawai, dapat diketahui perilaku pegawai yang dapat mendukung dan juga mengetahui persepsi, dan perilaku yang perlu dikembangkan untuk mewujudkan keselamatan pegawai.

\section{DAFTAR PUSTAKA}

Iriviranty, A. (2014). Analisis Budaya Organisasi dan Budaya Keselamatan Pasien Sebagai Langkah Pengembangan Keselamatan Pasien di RSIA Budi Kemuliaan Tahun 2014. Jurnal Administrasi Rumah Sakit, 1(3), 196-206. 
Masinambow, A. (2013). Analisis Faktor Faktor Yang Mempengaruhi Wajib Pajak Orang Pribadi Dalam Memenuhi Kewajiban Membayar Pajak Pada Kantor Pelayanan Pajak Pratama Manado. Jurnal Embal 1 (4), 1857-1867, diambil dari https://ejournal.unsrat.ac.id/index.php/emba/article/view/3394/2937

Pratami, W. C. A. (2017). Penerapan Metode Kuantitatif Terhadap Jumlah Permintaan Tenaga Kerja Perhotelan di Denpasar. Jurnal Bisnis Darmajaya 3 (1), 65-73, diambil dari https://jurnal.darmajaya.ac.id/index.php/JurnalBisnis/article/view/729/469

\section{UCAPAN TERIMA KASIH}

Penulisan artikel ini tidak akan pernah terwujud tanpa bantuan dari berbagai pihak. Oleh karena itu penulis ingin mengucapkan terima kasih kepada: 1) Kepala Biro Perencanan BATAN yang telah memberikan izin melakukan penelitian dan 2) teman-teman Biro Perencanaan yang telah berkenan memberikan data, masukan dan saran untuk penyempurnaan makalah ini. Sehingga penelitian ini dapat terwujud.

\section{PROFIL PENULIS}

Penulis Pertama merupakan Pegawai Negeri Sipil (PNS) Biro Perencanaan BATAN dengan jabatan Fungsional Perencana dengan memiliki latar belakang pendidikan S1 Akuntansi dan S2 Akuntansi Perpajakan. Penulis Kedua merupakan PNS Biro Perencanaan BATAN dengan jabatan Fungsional Perencana dengan memiliki latar belakang pendidikan S1 Teknik Elektro dan S2 Teknik Industri. 